\title{
Error Correction in Second Language Learning
}

\author{
Etleva Koni \\ Hatixhe Leka \\ University of Tirana University of Tirana, Faculty of Foreign Languages, Tirana, Albania \\ Email eekondi@yahoo.com E-mail gsejdini@yahoo.com
}

\section{Doi:10.5901/mjss.2015.v6n3s1p174}

\begin{abstract}
It is inevitable that all language learners make mistakes while acquiring a language. The stages and steps the learners follow help the teachers realize that the identification and analysis of errors provide them with feedback and useful information so that learners can have an effective acquisition of the language. This paper focuses on the importance of error correction, how much it is related to language fluency and accuracy. Through the analysis of a questionnaire we carried out, we observed how learners view correction, whether they consider it important in further developing their linguistic ability and acquiring accuracy.
\end{abstract}

Keywords: correction, accuracy, error, fluency, learning process

\section{Introduction}

All learners pass through similar stages of linguistic development when acquiring a language. No doubt, when learning a native language, children make plenty of mistakes and this is quite a natural part of language learning process. What a second language learner does in operating in the foreign language is not different from that of a child acquiring his/her native language.

In language teaching, mistakes cannot be avoided and the first thing that a teacher has to cope with is how to treat the mistakes. The topic of error correction has always brought controversy among many language teachers and researchers. Based on their own experiences on language learning, many teachers nowadays have very strong views about error correction, and some others, being influenced by the latest teaching methods (communicative approach), are often ambivalent toward it. In other words, depending on the research articles they have read related to error correction, some teachers may regard it as harmful, which prevents fluent communication, and some others might consider it beneficial and even very important for some grammatical structures.

But some important questions arise: What is the importance of correction? Should the teachers treat all the errors committed? What kind of feedback should they give?

\section{The Importance of Error Correction}

It is important to mention that error correction falls into two categories in second language classes: meaning-focused instruction and form-focused instruction (Long, 1996; Ellis, 2001).The meaning- focused instruction aims at developing the learner's communicative ability without paying any direct attention to form, considering language a system that helps the learner to freely express his or her ideas. While the form-focused instruction treats language as an object that is learned through the explicit lessons, aiming specific grammatical rules and structures.

Albanian traditional method of teaching considers accuracy important in the process of learning, which means that, anytime we encounter a mistake, we should directly correct it. According to the teachers, grammar represents a set of rules. Once you break a rule, you make a mistake. They directly get the red pen and correct the mistake. Then, the learner is supposed to repeat the correct structure many times. And that is the end of the problem. But this attitude may lead to learner's loss of interest to study or utilize the language to communicate. Thus, their linguistic creative ability may be strained (Erdogan, V., 2005). Under these circumstances, it is necessary that we introduce another teaching method, which aims communicative ability. The learners speak and practise the foreign language while the teachers pay no attention to their mistakes. The learners seem to speak a fluent language, but not always accurately, not exactly having an effective communication. This leads to a phenomenon called 'fluent fool.

In contrast to the traditional method of teaching, which pays attention to the linguistic accuracy but not fluency, the 
teaching method for communicative purposes aims fluency but not accuracy. This puts the accuracy and fluency in a position of contradiction.

It is quite clear that the relationship between the linguistic accuracy and fluency is the most effective way in language teaching and error correction is closely related to them (Erdogan, V., 2005).

What Corder (1973) points out below, is a summary of the view of error correction in foreign language teaching.

'Language learning is not parrot learning; we do not 'learn' or 'practice' examples.

They are the data from which we induce the system of the language. Skill in correction of errors lies in the direction of exploiting the incorrect forms produced by the learner in a controlled fashion.'

The thought that errors should be ignored, explains why some teachers consider the communicative approach tolerant. This teaching method allows the teachers and learners to be fluent speakers of an inaccurate language and as a consequence we have lower standards. However, it is important to point out that while all errors impede communication, some are a greater obstacle than some others. What impedes communication may not be what we traditionally call 'mistake'. If the syllabus of a foreign language aims at having language users who communicate freely, then we have priorities other than simply correcting and eliminating all the mistakes. Based on the learners' expected standards, the communicative approach underlies that a mistake is concrete and independent. The teachers can identify, treat or ignore it depending on the context.

A question that comes out is related to the reason why we need to have accurate speech. In 1954, the Modern Language Association published a pamphlet entitled Grammar in relation to language learning. In a section headed 'The necessity for accuracy in the study of languages in schools' it says:

The study of grammatical accuracy and function... is indispensable for the achievement of a reasonable standard of accuracy in the use of language...Looseness in the use of language leads to lose thinking and robs the language of its capacity for precise expression (Corbett, 1965):

It is quite clear that the authors of this article consider grammar important in having an accurate conversation. This is a common view among many linguists nowadays. However, many linguists, who are strongly for the communicative approach, admit that the grammatical accuracy is not always essential in having a meaningful communication. According to them, quite often ungrammatical structures do not convey less accurate messages. Nor are these structures necessarily indicative of muddled thought (Page, B., 1994).

Given the fact that some incorrect speech cannot be wrong, our focus on the language learning process is to understand on what terms we should classify that speech incorrect. The question is: If correct grammar is not important, then why should we learn the grammar of the language? What is the communicative value of the correct grammar?

For the supporters of the communicative approach, the answer is quite clear. Correct grammar has a social function. That tells the world something about the individual (Page, B., 1994).

Errors in a foreign language help us understand the language learning process and as a consequence the incorporation of the psychology of the learning process. Recently, this has been the focus in the literature on modern language teaching methods. Error correction provides the necessary information to understand the correct linguistic concept or rule. Thus, a better analysis of the incorrect structures gives account of what the learner knows and what he doesn't know. Correction enables the teacher not only to make the learner aware of the fact that his or her sentences are incorrect but also to provide useful information for him or her to come with the correct grammatical rule in the target language.

With the development of the communicative language, the importance of accuracy has quite often been neglected, encouraging more the fluent speaking in the foreign language. A more balanced teaching method, where both accuracy and fluency are prominent, would be more effective. To achieve grammatical accuracy the learner needs to pay attention to the form, that is, 'getting it right'. And this requires time. It is true that a learner is more accurate when more time is available. He can use this time to plan, monitor and fine-tune his or her speech.

Swain (1995) and Lyster (1993) state that 'a communicative oriented environment is not the only necessary condition for second language acquisition'. According to them, an effective way in improving the learner's performance is paying attention to the form based on the formal rules, while having activities focusing on communicative ability. Teachers attract the learner's attention to specific linguistic forms, covering the syllabus.

A well-informed teacher on error analysis is able to monitor the learner's errors and take precautions when necessary. Different kinds of tasks require different ways of treatment. Teacher's reaction to the mistake and the kind of feedback he or she gives, are usually determined by the importance the error carries in achieving the objective of the task.

While completing a task, it is usually recommended that mistakes in a fluent speaking should not be corrected. These mistakes are mentioned and explained when the speech is over. If the feedback is on the form, structure or 
content is to be determined by the objective of the activity. If the objective is to practise a particular grammatical issue, then it is important to give feedback on the form or structure (Ur, 1996).

If the role of the grammar is considered to be indispensable for the achievement of the communicative ability, even the spoken language is important. Based on this point of view, the feedback is a useful device for the teachers. Through this device, the teacher helps the learner to reformulate the linguistic data he or she already possesses, which results in the learner further developing a more accurate language system. However, the learner cannot suddenly achieve accuracy in the spoken language. It is important that he values accuracy. Thus, it is fundamental that the learner receives clear feedback, which reveals that the mistake made brings unintelligible messages. Knowing that he/she is closely monitored helps the learner pay more attention to the form. The best that can be hoped for is continuous progress on accuracy.

Thus, we can strongly admit that correction should not mean insisting on everything being absolutely correct. It means helping learners to become more accurate in their use of language (Edge, J.,1989 ).

In the following part, through the analysis of a questionnaire, we present learners' viewpoint on error correction.

\section{Methodology of Research}

In order to know the attitude learners have toward error correction and their opinion related to the type of correction the teacher uses, we observed two classes of levels A2 and B1 in the foreign language high school, in Tirana. The teacher was the same in both classes, an aspect that could help us verify if the teacher used the same kind of error correction in both settings. In other words, our main focus in the survey was to figure out the attitudes and beliefs learners have toward correction.

The following analysis came from the observation of two groups. In level A2 class there were 30 participants, aged 15-16, 10 males and 20 females, while in level B1 class there were 25 participants, aged 16-17, 7 males and 18 females. The material used is New framework 2 and 3, Richmond publishing. To collect our data we observed three units in each book.

At the end of our observation, learners were asked to answer the questions in a questionnaire related to their opinion about the teacher's corrective feedback and their belief about error correction.

\section{Data Analysis of the Questionnarie}

The questionnaire contained seven questions with three possible answers (absolutely agree, partially agree, disagree).

* The first question (1): When you get new (lexical, grammatical) information, do you prefer to take that little by little or all at once?

22 learners in level A2 and 20 learners in level B1 agree to take new lexical and grammatical information little by little, which shows that the majority of learners are interested in understanding the form of the linguistic items and not just the context they are found in.

* The second question (2): Do you like using new structures despite not being absolutely sure that they are accurate?

This question had a more balanced answer. Most of the learners, 15 learners in level A2 and 19 learners in level B1, partially agree to use new information without having fully acquired the correct use of a certain word or structure. These results confirm the learners' interest in language accuracy.

* The third question (3): Do you like pair work activity because the teacher cannot correct you all the time, and as a result you speak freely?

The answers were 'partially agree', 14 learners in level A2 and 18 in level B1. This means that there are cases when learners prefer feedback, whereas in some others they prefer to communicate without paying attention to the form. Thus, there is some partial interest from the students in the speaking fluently without being corrected.

* The fourth question (4) is related to the third question: Do you usually plan and monitor your speaking in order to avoid making mistakes?

Most of the learners, 14, in level A2 partially plan and monitor their speaking, while 17 learners in level B1 prefer to monitor themselves in order to have an accurate speaking. This indicates that the more developed linguistic competence the learners have, the more they worry about accuracy.

* The fifth question (5): How do you feel when you make mistakes?

Even though the learners try to have accurate speaking, many of them, 23 in level A2 and 24 in level B1, 
consider mistakes important in improving their linguistic competence.

* The sixth question (6): Do consider effective the immediate corrective feedback given by the teacher in communicative settings?

This is a question that represents the belief learners have about immediate correction. Despite communication being the main goal, the majority of learners, 26 in level A2 and 24 in level B1, consider accuracy essential in the language learning process, that is, they agree with the teacher's correction. This is further observed in the results of the seventh question (7).

* The seventh question (7): Do you like the teacher's type of correction (which encouraged both accuracy and fluency)?

The answers to the question indicate that most learners, 18 in level A1 and 21 in level B1, appreciate the interactive environment the teacher provides.

Thus, developing the linguistic accuracy and fluency requires encouragement and motivation.

\section{Conclusion}

Although our survey focuses on only one teacher's performance, it allowed us to fully analyze the different kinds of feedback offered by the teacher in an environment which aims developing not only the accuracy but also the communicative ability. In many instances the teacher explicitly corrects the mistakes and makes sure that learners are aware of the correction. We observed a very good learner-teacher relationship and as consequence, an effective interaction between them. Many of the learners were fully aware of the correction, reacted positively toward it and considered it to be very important in developing their linguistic competence.

Error analysis depends on the teacher's attitude toward an error and the attitudes directly affect the teacher's behaviour and method in the second language class. The ability a teacher has to spontaneously use different kinds of correction, further encourages the learners to interact and get motivated.

Errors being part of the learning process and correction part of the teaching process are interrelated with each other in the teacher's work. The teacher considers himself part of the learning process, and as a result, teaching serves the learning process. A learner greatly needs to feel that his linguistic ability in the foreign language is developing, and of course, through the teacher's help. It is very important that a teacher be informed about different theories and fully understand them, so he/she can integrate all of them in his teaching and why not, if having a solid academic knowledge, a teacher can even challenge these theories.

It is quite obvious that a sensible use of error correction in the classroom can help provide an optimal environment for foreign language learning.

\section{References}

Erdogan, V. (2005). Contribution of error analysis to foreign language teaching. Mersin University Journal of the Faculty of Education, Vol. 1, Issue 2.

Corder, S.P. (1984). Idiosyncratic dialects and error analysis in Richards, Jack C. Error analysis. Longman, 158-172.

Corder, S.P. (1988). Pedagogic Grammars. In William Rutherford, et al. (eds), Grammar and Second Language Teaching. New York: Newbury.

Corbett, R. (1965). No great matter. Modern Languages XLVI, 3.

Norrish J. (1983). Lnaguage Learners and Their Errors. Macmillion Publishers.

Page, B., (1994). Why do I have to get it right anyway in Swarbric Ann. Teaching modern languages. Open Univesity, 121-124.

Penny Ur. (1996). A Course in Language Teaching: Practice of Theory. Cambridge University Press.

Richards \& Sampson. (1984). The study of learner English. in Richards, Jack C., "Error Analysis". Longman, 3-18.

Orlich, et al. (2004). Teaching Strategies: A Guide to Effective Instruction. Houghton Mifflin. 